\title{
Complications associated with pre-hospital open thoracostomies: a rapid review
}

\author{
Stian Mohrsen ${ }^{1,2^{*}}$ (B) Niall McMahon ${ }^{1}$, Alasdair Corfield ${ }^{1}$ and Sinéad McKee ${ }^{3}$
}

\begin{abstract}
Background: Open thoracostomies have become the standard of care in pre-hospital critical care in patients with chest injuries receiving positive pressure ventilation. The procedure has embedded itself as a rapid method to decompress air or fluid in the chest cavity since its original description in 1995, with a complication rate equal to or better than the out-of-hospital insertion of indwelling pleural catheters. A literature review was performed to explore potential negative implications of open thoracostomies and discuss its role in mechanically ventilated patients without clinical features of pneumothorax.

Main findings: A rapid review of key healthcare databases showed a significant rate of complications associated with pre-hospital open thoracostomies. Of 352 thoracostomies included in the final analysis, $10.6 \%(n=38)$ led to complications of which most were related to operator error or infection $(n=26)$. Pneumothoraces were missed in $2.2 \%(n=8)$ of all cases.

Conclusion: There is an appreciable complication rate associated with pre-hospital open thoracostomy. Based on a risk/benefit decision for individual patients, it may be appropriate to withhold intervention in the absence of clinical features, but consideration must be given to the environment where the patient will be monitored during care and transfer. Chest ultrasound can be an effective assessment adjunct to rule in pneumothorax, and may have a role in mitigating the rate of missed cases.
\end{abstract}

Keywords: Emergency medical services, Critical care, Thoracic injuries, Pneumothorax, Thoracostomy, Intraoperative complications

\section{Background}

In addition to the oesophagus and lymphatic vessels, the thoracic cavity contains several life-sustaining structures including the heart and great vessels, airways, and lungs [1]. Injury to any of these can place a person at immediate threat of severe disability or death, making chest trauma a well-acquainted adversary of emergency prehospital care providers. Even though significant chest injuries are associated with adverse outcomes, they can manifest late and have proven difficult to identify on

*Correspondence: stian.mohrsen@nhs.scot; stian.mohrsen@stir.ac.uk 1 ScotSTAR, Emergency Medical Retrieval Service, 180 Abbotsinch Road, Paisley PA2 3RY, UK

Full list of author information is available at the end of the article clinical examination [2, 3]. Leech et al. [4] list closed tension pneumothorax (T-PTX) as the most common severe pathology in major chest trauma (1 in 250), a condition where air is increasingly introduced to the pleural space without an ability to escape [1]. This can develop over a matter of minutes or several hours [5], and occurs when a conduit is created by a rupture of lung tissue or an open wound through the chest wall, or a combination of the two. Increasing volume of air in one side of the pleural cavity interferes with pleural adhesion and disrupts the negative-pressure mechanism normal ventilation relies upon. An ever-increasing pleural volume compresses the ipsilateral lung further inhibiting alveolar ventilation area, and rising pressure shifts structures such as the vena cavae contralaterally which reduces cardiac preload original author(s) and the source, provide a link to the Creative Commons licence, and indicate if changes were made. The images or other third party material in this article are included in the article's Creative Commons licence, unless indicated otherwise in a credit line to the material. If material is not included in the article's Creative Commons licence and your intended use is not permitted by statutory regulation or exceeds the permitted use, you will need to obtain permission directly from the copyright holder. To view a copy of this licence, visit http://creativecommons.org/licenses/by/4.0/. The Creative Commons Public Domain Dedication waiver (http://creativeco mmons.org/publicdomain/zero/1.0/) applies to the data made available in this article, unless otherwise stated in a credit line to the data. 
and eventually causes circulatory collapse. Significant haemorrhage into the pleural cavity can present a similar mass effect on the lung and mediastinal organs, but less often creates tension and introduces significant intravascular volume depletion as a co-pathology $[4,6]$.

Immediate mitigation of large T-PTX involves the release of air from the pleural cavity. In its simplest form this is done by inserting an open intravenous cannula through the chest wall and can be performed in the spontaneously breathing patient to alleviate high intrathoracic pressures. This is a safe intervention when applied in the correct circumstances [7] but has also been highlighted as often inadequate by Leigh-Smith \& Harris [5] in 2004 and in several studies since $[8,9]$.

Traditionally, definitive treatment has been tube thoracostomies which involve performing a thoracic incision and placing an indwelling catheter attached to a one-way drainage system, to prevent air from re-entering the chest cavity [10]. More recently, Deakin et al. [11] described an open thoracostomy technique in the positive pressureventilated patient where altered ventilation physiology would allow an open conduit between the chest and environment without respiratory failure. Several authors have emphasised the success of this technique [12-14], which now is considered standard treatment for patients in traumatic cardiac arrest, or those who are positive pressure-ventilated with significant pneumo- or haemothorax with ventilatory compromise, where the skill is available $[4,15-17]$. A recent systematic review by Sharrock et al. [18] sought to compare the safety and efficacy of needleand open thoracostomies performed by non-physicians but was unable to establish one as definitively superior.

\section{Additional file 1 contains an illustration of finger thoracostomies}

Simple thoracostomy: (a) The 'triangle of safety' is identified by the centre of the axilla, the lateral aspect of musculus latissimus dorsi, and the lateral pectoralis major at the line of the nipple, with the arm fully abducted. (b) A bold incision is made through subcutaneous tissue in the fifth intercostal space at the anterior axillary line. (c) Muscle tissue is then dissected using a blunt instrument e.g., a set of arterial forceps, creating a canal to the parietal pleura which is then breached for access to the pleural cavity. A hiss of air, or ooze of blood or pus may present at this point, depending on underlying pathology. (d) The pleural cavity is explored using a finger, assessing for the position of the lung and any adhesions. The resulting canal is left open to allow air or fluid to escape and prevent compression of the lung. (Illustration by Megan Worsfold).

National guidance only describes the application of pre-hospital open thoracostomies in patients where there is a clinical suspicion of tension-pathology $[4,16]$. However experience has shown this practice is implemented by some as a preventative measure, where a pneumothorax (PTX) may or may not be present, to avoid complications e.g., unrecognised T-PTX during transport. Decompression of significant PTX regardless of manifested tension has been promoted in secondary literature [19]. However, this concerns an interfacility setting with the ability to confirm the diagnosis with a chest $x$-ray, but the authors do not discuss what to do when there is an absence of clinical indicators. The Occult Pneumothoraces in Critical Care (OPTICC) trial [20] suggests it may be appropriate to observe patients receiving positive pressure ventilation (PPV) without overt signs of PTX, but this was an in-hospital study where close monitoring and immediate action was readily available. Pre-hospital critical care is typically delivered with a clinician-topatient ratio of 2:1 with appropriate monitoring and the ability to decompress a developing tension as it presents. However environmental considerations such as vibration, dim lighting and noise are a few examples of potential barriers to identifying rapid changes in clinical condition [19] in the pre-hospital setting. A literature review was performed to explore potential negative implications of open thoracostomies and discuss its role in mechanically ventilated patients without clinical features of pneumothorax.

\section{Methods \\ Selection criteria}

A review across several databases was performed to assess the rate of complications in pre-hospital open thoracostomies. Only patients receiving positive pressure ventilation were included as normal respiratory physiology precludes the need for open thoracostomies in the spontaneously breathing patient $[4,16]$. Only cases where at least one thoracostomy was performed pre-hospital was included, as this is the environment of practice the question relates to. The patient with chest injuries is emphasised, but papers discussing PTX from medical causes were also included if pre-hospital thoracostomy was a treatment strategy used.

Open thoracostomy is here defined as a surgical procedure where sharp dissection is used to break the skin of the chest in the 4-5th intercostal space in the anterior axillary line, following which blunt dissection and a finger-sweep creates a conduit between the pleura and the environment but without placing a chest tube. This can include cases where the procedure was performed without a clear clinical need, based on signs or symptoms of significant chest trauma to both sides of the chest or deranged physiology; or where only the side(s) of the chest that were injured were opened. Indwelling chest 
drains were excluded from the review if placed in the pre-hospital environment, as this procedure carries other risks of complication and would be rare in current prehospital practice [10, 21].

Outcomes measured were defined as:

- rate of iatrogenic injury to other structures; bleeding including iatrogenic haemothorax; loss of sensation; chronic neuralgia

- wound infection or empyema

- misplacement

- missed contralateral pathology requiring decompression

- delayed healing defined as time dependent on thoracic drainage, ventilation, or surgical wound care (Table 1).

\section{Search strategy}

The PROSPERO and Cochrane Reviews databases were interrogated for any reviews answering the clinical question [22, 23]. No relevant articles were found in Cochrane CENTRAL database for clinical trials. Two related best evidence topics by Pritchard [12, 24] relating to patients with chest injuries and in traumatic cardiac arrest respectively were identified in the BestBETs database [25], but differs from this review as it excluded paediatric patients and included papers where indwelling tubes were inserted pre-hospital and were therefore excluded.

Searchable terms were developed from keywords discovered during scoping searches. Terms were connected using truncation and wildcards, and the "AND" or "OR" Boolean logic-operators: pre"hospital OR out-of-hospital AND; thoracostom*; AND iatrogeni* OR complication* OR infection OR empy?ema OR delay*. Subject headings or MeSH-terms were used across the Cochrane and Ovid interfaces, identified by using the interfaces' integral heading-browsers. Terms related to age and ventilation status were withheld from the search, and excluded at screening if not agreeing with selection criteria to ensure a sufficient sensitivity and search yield.

Table 1 Selection criteria

\begin{tabular}{ll}
\hline Inclusion & Pre-hospital setting \\
& Positive pressure ventilated \\
& Single or bilateral thoracostomies \\
& Published 2000-2021 \\
& Not English language \\
Exclusion & Pre-hospital chest drain \\
& Traumatic cardiac arrest \\
& Needle thoracostomy only \\
& Case-control/qualitative designs \\
\end{tabular}

Searches were performed across titles and abstracts in Scopus (Elsevier), CINAHL (HDAS), Medline (Ovid SP) and Embase (Ovid SP) on 6th March 2021 (Table 2). Papers were limited to those written in English and published between 2000 to 2021. Results were uploaded to Endnote X9 (3.3, Cite While You Write) referencing software and deduplicated, before manual screening of abstracts and full texts against selection criteria.

Table 2 Search strategy

\begin{tabular}{|c|c|c|c|c|c|}
\hline & Terms & Scopus & CINAHL & Medline & Embase \\
\hline 1 & Pre*hospital & 73661 & 18419 & 12588 & 17439 \\
\hline 2 & Out-of-hospital & 52710 & 6787 & 12624 & 18749 \\
\hline 3 & $\$ \mathrm{SH} / \mathrm{MeSH}$ & $\mathrm{N} / \mathrm{A}$ & 13537 & 47783 & 48802 \\
\hline 4 & $\mathrm{OR} / 1-3$ & 109233 & 23647 & 61641 & 78986 \\
\hline 5 & Thoracostom* & 6926 & 773 & 2325 & 3262 \\
\hline 6 & $\$ \mathrm{SH} / \mathrm{MeSH}$ & $\mathrm{N} / \mathrm{A}$ & 1181 & 2997 & 1243 \\
\hline 7 & OR/5-6 & $\mathrm{N} / \mathrm{A}$ & 1712 & 3018 & 3790 \\
\hline 8 & latrogeni* & 207270 & 8983 & 32791 & 44850 \\
\hline 9 & Complication* & 3097082 & 675868 & 947927 & 1390713 \\
\hline 10 & Adverse & 1799456 & 583316 & 534469 & 831783 \\
\hline 11 & Infection & 4805210 & 384789 & 1142202 & 1458125 \\
\hline 12 & Sepsis & 436334 & 31176 & 100668 & 156477 \\
\hline 13 & Empy*ema & 30485 & 1605 & 9686 & 11618 \\
\hline 14 & Bronchiectas* & 36202 & 2132 & 10000 & 16054 \\
\hline 15 & Pain & 2147032 & 322318 & 649788 & 969019 \\
\hline 16 & $\$ \mathrm{SH} / \mathrm{MeSH}$ & $\mathrm{N} / \mathrm{A}$ & 35595 & 103346 & 489506 \\
\hline 17 & OR/8-16 & $\mathrm{N} / \mathrm{A}$ & 1624316 & 3090405 & 4448115 \\
\hline 18 & Delay* & 2801825 & 106906 & 493565 & 670336 \\
\hline 19 & Prolong* & 1427447 & 56571 & 389541 & 524377 \\
\hline 20 & $\mathrm{OR} / 18+19$ & N/A & 159064 & 856233 & 1155597 \\
\hline 21 & Healing & 907080 & 73579 & 183322 & 234950 \\
\hline 22 & Recovery & 3017527 & 106412 & 463874 & 614261 \\
\hline 23 & $\mathrm{OR} / 21+22$ & $\mathrm{~N} / \mathrm{A}$ & 164306 & 640509 & 839667 \\
\hline 24 & AND/20 + 23 & 517883 & 11516 & 55984 & 79312 \\
\hline 25 & $\$ \mathrm{SH} / \mathrm{MeSH}$ & $\mathrm{N} / \mathrm{A}$ & 54375 & 92138 & 439343 \\
\hline 26 & $\mathrm{OR} / 24+25$ & $\mathrm{~N} / \mathrm{A}$ & 65458 & 147171 & 515468 \\
\hline 27 & $\mathrm{OR} / 17+26$ & 10240619 & 1656484 & 3180724 & 4756714 \\
\hline 28 & AND/4+7+27 & 31 & 31 & 47 & 49 \\
\hline
\end{tabular}

$\$ \mathrm{SH} / \mathrm{MeSH} / \mathrm{Terms}=$ Subject headings $/ \mathrm{MeSH}$

For Scopus: N/A

For CINAHL: (3) "Prehospital Care"; (6) "Thoracostomy+"; (16) "Postoperative Hemorrhage" OR "Postoperative Pain" OR "Surgical Wound Infection" OR "latrogenic Disease"; (25) "Treatment Duration" OR "Length of Stay"

For Medline: (3) Emergency Medical Services/; (6) Thoracostomy/; (16) latrogenic Disease/or Pain, Postoperative/or Postoperative Haemorrhage/or Surgical Wound Infection/; (25) Duration of Therapy/or Length of Stay/

For Embase: (3) Emergency care/; (6) Thoracostomy/; (16) Postoperative complication/OR Postoperative haemorrhage/or Postoperative infection/OR Postoperative inflammation/OR Postoperative pain/OR Surgical infection/OR Surgical injury/; (25) Treatment duration/OR "Length of stay"/ 


\section{Additional file 2 contains a PRISMA flowchart demonstrating the search and screen process}

\section{Data collection and analysis}

Qualitative analysis of each paper was performed (Additional file 3: Table 1) and rated using the OCEBM Levels of Evidence [26] and GRADE criteria [27]. Data pertaining to complications were extracted, and common types of iatrogenesis or complications were clustered. Incidence of complications was calculated and is presented as counts and percentages of all complications and all thoracostomies. One paper was excluded from quantitative analysis as it did not follow patients beyond handover to the emergency department [13].

\section{Results}

A total of five papers met the selection criteria after full text screening, all pertaining to procedures performed pre-hospital but only four describing outcomes beyond hospital admission [13, 14, 28-30]. The papers included a total of 350 patients receiving 427 thoracostomies (excluding traumatic cardiac arrest), of which 386 (90.4\%) were in the pre-hospital environment and 41 (9.6\%) were in hospital. Two-hundred-and-twenty-four patients (64\%) were followed up past admission with a mortality rate of $28.5 \%(n=64)$.

\section{Additional file 3 contains a landscape table of included studies with analysis}

\section{Indications and procedure}

Open thoracostomies are universally indicated in the presence of a large PTX in patients receiving PPV, as this is associated with an increased risk of developing tension pathology [31, 32]. Massarutti et al. [14] defined a clinical diagnosis of simple PTX as decreased breath sounds, subcutaneous emphysema, serial rib fractures with chest wall instability, flail chest or penetrating chest wounds. Aylwin et al. [30] applied similar criteria but added the presence of a unilateral wheeze to the list of clinical signs and added a wider range of indications including undifferentiated hypotension, or unilateral signs of a PTX in the presence of hypoxia or hypotension. Aylwin et al. [30] used T-PTX as the indication for the procedure defined as hypoxia, hypotension, absent breath sounds and tracheal shift. Conversely, Massarutti et al. [14] defined T-PTX based on the result of the procedure, as determined by an apparent hiss of air and/or rapidly stabilising vital signs following the procedure. Chesters et al. [13], Hannon et al. [28] and Quinn et al. [29] did not elaborate on their clinical indications but included chest injuries presenting a high risk of PTX, or unexplained hypoxia or hypotension in all patients receiving PPV. All papers agreed on finger thoracostomies as appropriate routine measures in traumatic cardiac arrest, and described the procedure uniformly, most referring to the initial description of the technique by Deakin et al. [11] in 1995.

\section{Complications}

Of the 352 procedures followed up past admission, 10.6\% $(n=38)$ were associated with complications and of these $7.3 \%(\mathrm{n}=26)$ were caused by procedural error and subsequent injury, infection, or treatment failure, while missed or recurring PTX accounted for $3.4 \%(n=12)$.

Of the 38 complications identified in this review (Table 3), iatrogenic injury including injury to underlying organs, unintended bleeding, induced haemothorax or unnecessarily created thoracostomies was most common $(28.9 \%, n=11)$. Failure to decompress underlying PTX despite attempt and misplaced incisions accounted for five (13.1\%) and eight cases (21\%) respectively, and missed PTX and recurrent tension accounted for eight (21\%) and four (10.6\%) cases, respectively. Only two cases $(5.2 \%)$ of post-procedure infection were identified on follow-up, but of note, the use of prophylactic antibiotics is not discussed throughout the papers and can therefore not be assessed reliably. Excluded from these data is the study by Chesters et al. [13] which did not include any follow-up beyond the pre-hospital phase.

\section{Discussion}

Pre-hospital open thoracostomies have shown to be effective at relieving T-PTX and retain patency, avoiding the time-consumption and complications associated with inserting a drainage tube [33]. Findings from this review support this with only $1.1 \%$ of PTX re-tensioning postprocedure, but there is an apparent paucity of studies assessing patient-focused outcomes from thoracostomies with only three of the five identified papers attempting follow-up beyond pre-hospital or emergency department care $[14,28,30]$.

Table 3 Complications

\begin{tabular}{lrll}
\hline Complication & No & \% $(\boldsymbol{n}=\mathbf{3 8})$ & \% $(\boldsymbol{n}=\mathbf{3 5 2})$ \\
\hline latrogenic injury & 11 & 28.9 & 3.1 \\
Failed procedure & 5 & 13.1 & 1.4 \\
Misplacement & 8 & 21.0 & 2.3 \\
Infection & 2 & 5.2 & 0.5 \\
Recurrent PTX & 4 & 10.5 & 1.1 \\
Missed PTX & 8 & 21.0 & 2.2 \\
Total & 38 & 100 & 10.6 \\
\hline
\end{tabular}


Careful balancing of benefit and harm, in line with the core principles of biomedical ethics [33] is required with any invasive procedure. Open thoracostomies are not benign with an overall procedural complication rate of 7.4\% (excluding missed and recurrent PTX) and are associated with other complications such as long-term pain and cosmetic implications [10,34], although these were not discussed in the papers in this review.

Finger thoracostomies in trauma are appropriate in circumstances where the patient has suffered chest injuries and is in cardiac arrest $[15,17]$. It is also an established intervention in tension pneumothorax $[15,16]$, but the criteria for diagnosis are inconsistent between the papers in this review [13, 14, 28-30]. Unilateral chest pathology following trauma with features of reduced or absent air entry, with persistent or worsening hypoxia despite other measures, and/or features of shock or high ventilator airway pressures, should prompt consideration of a tension pathology requiring decompression $[9,16,31]$. However, there are many other potential causes for hypoxia, shock, and high airway pressures in the positive pressure ventilated trauma patient. Therefore, the decision to perform thoracostomy could be helped by using a checklist to ensure other less invasive causes are ruled out, before committing the patient to a surgical procedure [35].

Pre-hospital practice has evolved tremendously since Deakin et al. [11] first described the open thoracostomy method with the recent introduction of point-of-care ultrasound (POCUS) [36]. The technique is increasingly popular and advocated as an adjunctive decision-making tool in chest trauma [15]. POCUS has demonstrated high positive and negative predictive values, but due to significant inter-rater differences it is currently regarded too unreliable in completely ruling out pathology $[37,38]$. Chest wall surgical emphysema in particular significantly reduces the utility of POCUS. That said, services that can ensure adequate training and competence should consider incorporating POCUS assessment into their guidelines. Further research on the utility of POCUS in pre-hospital chest injury management may help define those patient groups most likely to benefit from pre-hospital finger throactostomy.

\section{Limitations}

This review has several limitations. All the included studies have used purposive sampling introducing potential selection bias, in this case patients requiring pre-hospital thoracostomies. This patient group typically suffers other major injuries associated with high morbidity and mortality and could confound outcomes, which cannot be adjusted for effectively with retrospective study designs and no comparison groups. Sample sizes are small and heterogenous; additionally, several of the papers demonstrated a high loss to follow-up with a mean of $71.4 \%(n=64 / 224)$ of patients followed up to survival [14, 28-30]. This attrition bias could significantly affect the outcomes observed in the sample population hiding procedural complications as contributing to mortality in these patients. The retrospective nature of three of the studies [13, 28, 29] raises the possibility of reporting bias from inadequate or inaccurate notetaking. Conversely, prospective studies could encourage clinicians to create notes portraying more favourable outcomes than they otherwise would, knowing their practice is being assessed. Aylwin et al. [30] and Quinn et al. [29] included thoracostomies performed in the emergency department in their data which reduces the generalisability of these results to pre-hospital practice. The study by Hannon et al. [28] also included follow-up data on three cases who initially were in cardiac arrest which is not directly applicable to the selection criteria for this review.

\section{Conclusion}

Pre-hospital thoracostomies are associated with a 10.6\% complication rate based on the evidence identified in this review, most of which are due to operator error as opposed to unresolved or missed pathology. An open thoracostomy technique is likely to be as safe or safer than tube thoracostomies and remains the preferred option unless a tube is indicated for other reasons. Occult pneumothoraces can develop tension with subsequent shock or cardiac arrest, but it may be appropriate to withhold intervention in the absence of clinical features depending on the situation rather than 'empirical' thoracostomy. Clinicians should consider the environment where the patient will be monitored during care and transfer, and chest ultrasound can be used as an adjunct to assessment. Positive findings of pneumothorax on ultrasound may support a decision to decompress, but a normal ultrasound cannot exclude pathology and continuous patient monitoring remains pertinent. Existing evidence is too weak to establish definitive data on complications following pre-hospital thoracostomies, but this could be improved with prospective observational research with adequate follow-up beyond hospital admission.

\section{Abbreviations}

POCUS: Point-of-care ultrasound; PPV: Positive pressure ventilation; PTX: Pneumothorax; T-PTX:Tension pneumothorax.

\section{Supplementary Information}

The online version contains supplementary material available at https://doi. org/10.1186/s13049-021-00976-1.

Additional file 1. Figure 1: Illustration of an open thoracostomy. 
Additional file 2. Figure 2: PRISMA flowchart of the search and screen process.

Additional file 3. Table 1: Landscape table of included studies with summary of analysis.

\section{Acknowledgements}

The corresponding author would like to acknowledge the Emergency Medical Retrieval Service for the support to complete this work as part of a postgraduate degree and towards publication, and the University of Stirling for funding the publication of the article. Thank you to Megan Worsfold for illustrating the thoracostomy procedure and allowing its use towards this publication.

\section{Authors' contributions}

Methods, searching, review and manuscript by SMo. Manuscript review and revision by NM, SMc, and AC. All authors read and approved the final manuscript.

\section{Authors' information}

SMo works as an advanced retrieval practitioner with the ScotSTAR Emergency Medical Retrieval Service, and as a paramedic lecturer with the Faculty of Health Sciences and Sport at the University of Stirling. NM works as a consultant in emergency medicine with the ScotSTAR Emergency Medical Retrieval Service, and at the emergency department of Royal Alexandra Hospital in Paisley.

AC works as a consultant in emergency medicine with the ScotSTAR Emergency Medical Retrieval Service, and at the emergency department of Royal Alexandra Hospital in Paisley.

SMc works as a lecturer in nursing at the Glasgow Caledonian University.

\section{Funding}

Article processing fees funded by the University of Stirling.

\section{Availability of data and materials}

All data generated or analysed during this study are included in this published article through (1) tables included in the paper, and (2) the published articles included in the review.

\section{Declarations}

\section{Competing interests}

None of the authors have any relevant competing interests to disclose.

\section{Author details \\ ${ }^{1}$ ScotSTAR, Emergency Medical Retrieval Service, 180 Abbotsinch Road, Pais- ley PA2 3RY, UK. ${ }^{2}$ Faculty of Health Sciences and Sport, University of Stirling, Stirling FK9 4LA, Scotland, UK. ${ }^{3}$ Department of Nursing, School of Health and Life Sciences, Glasgow Caledonian University, Cowcaddens Road, Glas- gow G4 OBA, Scotland, UK.}

Received: 10 September 2021 Accepted: 4 November 2021

Published online: 04 December 2021

\section{References}

1. Moini J. Anatomy and physiology for health professionals. 3rd ed. Burlington: Jones \& Bartlett Learning; 2020.

2. Augustin P, Guivarch E, Pellenc Q, Castier Y, Boudinet S, Tanaka S, et al. Performance of pre-hospital evaluations in ruling out invasive chest stab wounds. Scand J Trauma Resusc Emerg Med. 2020. https://doi.org/10. 1186/s13049-020-00725-w.

3. Ebrahimi M, Vaziri M, Pishbin E, Reihani H, Akhavan R, Dost ER, et al. Comparison of diagnostic value of clinical examination and routine radiography in diagnosis of chest injury in stable blunt trauma patients. J Res Med Dent Sci. 2019;7(1):88-91.

4. Leech C, Porter K, Steyn R, Laird C, Virgo I, Bowman R, et al. The pre-hospital management of life-threatening chest injuries: a consensus statement
[Internet]. 2016 [cited 4 March 2021]. Available from: https://fphc.rcsed.ac. uk/media/1788/management-of-chest-injuries.pdf.

5. Leigh-Smith S, Harris T. Tension pneumothorax - time for a re-think? Emerg Med J. 2004;22(1):8-16. https://doi.org/10.1136/emj.2003.010421.

6. Magnone S, Gotti R, Capponi MG, Paderno N, Maraglino C, Cadei M, et al. Tension hemothorax due to iatrogenic subclavian artery perforation: hybrid management of a very rare complication. Int I Surg Case Rep. 2019;1(60):323-6. https://doi.org/10.1016/j.ijscr.2019.06.024.

7. Wernick B, Hon HH, Mubang RN, Cipriano A, Hughes R, Rankin DD, et al. Complications of needle thoracostomy: a comprehensive clinical review. Int J Crit Illn Inj Sci. 2015;5(3):160-9.

8. Aho JM, Thiels CA, El Khatib MM, Ubl DS, Laan DV, Berns KS, et al. Needle thoracostomy: clinical effectiveness is improved using a longer angiocatheter. J Trauma Acute Care Surg. 2016;80(2):272-7. https://doi.org/10. 1097/ta.00000000000000889.

9. Kaserer A, Stein P, Simmen H, Spahn DR, Neuhaus V. Failure rate of prehospital chest decompression after severe thoracic trauma. Am J Emerg Med. 2016;35(3):469-74. https://doi.org/10.1016/..ajem.2016.11.057.

10. Kwiatt M, Tarbox A, Seamon MJ, Swaroop M, Cipolla J, Allen C, et al. Thoracostomy tubes: a comprehensive review of complications and related topics. Int J Crit IIIn Inj Sci. 2014;4(2):143-55. https://doi.org/10.4103/ 2229-5151.134182.

11. Deakin $C D$, Davies $G$, Wilson $A$. Simple thoracostomy avoids chest drain insertion in prehospital trauma. J Trauma Acute Care Surg. 1995;39(2):373-4

12. Pritchard, J. Prehospital finger thoracostomy in patients with chest trauma. BestBETs. 2017. Available from: https://bestbets.org/bets/bet. php?id=2903.

13. Chesters A, Davies G, Wilson A. Four years of pre-hospital simple thoracostomy performed by a physician-paramedic helicopter emergency medical service team: a description and review of practice. Trauma. 2016;18(2):124-8. https://doi.org/10.1177/1460408615619197.

14. Massarutti D, Trillo G, Berlot G, Tomasini A, Bacer B, D'orlando L, et al. Simple thoracostomy in prehospital trauma management is safe and effective: a 2-year experience by helicopter emergency medical crews. Eur J Emerg Med. 2006;13(5):276-80. https://doi.org/10.1097/00063110200610000-00006.

15. American College of Surgeons. Advanced trauma life support: student course manual. 10th ed. Chicago: American College of Surgeons; 2018.

16. National Institute of Health and Care Excellence. Major trauma: assessment and initial management [Internet]. 2016 Feb 17 [cited 20 March 2021] (Clinical Guideline [NG39]). Available from: https://www.nice.org. uk/guidance/NG39/chapter/Recommendations\#management-of-chesttrauma-in-prehospital-settings.

17. Crewdson K, O'meara M, Lockey DJ, Porter KM. Management of traumatic cardiac arrest [Internet]. 2018 Oct [cited 8 March 2021]. Available from: https://fphc.rcsed.ac.uk/media/2577/tca-submission-oct-2018.pdf.

18. Sharrock K, Shannon B, Gonzalez CG, St. Clair T, Mitra B, Noonan M, Fitzgeral M, Olaussen A. Prehospital paramedic pleural decompression: a systematic review. Injury (forthcoming).

19. Low A, Hulme J. ABC of transfer and retrieval medicine. Chichester: Wiley Blackwell; 2015

20. Clements TW, Sirois M, Parry N, Roberts DJ, Trottier V, Rizoli S, et al. OPTICC: A multicentre trial of occult pneumothoraces subjected to mechanical ventilation: the final report. Am J Surg. 2021;221(6):1252-8. https://doi.org/10.1016/j.amjsurg.2021.02.012.

21. Kong VY, Oosthuizen GV, Sartorius B, Keene C, Clarke DL. An audit of the complications of intercostal chest drain insertion in a high volume trauma service in South Africa. Ann R Coll Surg Eng. 2014;96(8):609-13. https://doi.org/10.1308/003588414X14055925058599.

22. Cochrane Library. Cochrane Reviews [Internet] 2021. [cited 7 March 2021] Available from: https://www.cochranelibrary.com/cdsr/reviews.

23. University of York. PROSPERO, National Institute for Health Research [Internet]. [cited 13 March 2021] Available from: https://www.crd.york.ac. UK/PROSPERO/.

24. Pritchard, J. Prehospital finger thoracostomy in patients with traumatic cardiac arrest. BestBETs. 2017 Aug 21. Available from: https://bestbets. org/bets/bet.php?id=2908.

25. BestBETs. BestBETs database [Internet]. [cited 5 March 2021]. Available from: https://bestbets.org/database/browse-bets.php. 
26. OCEBM Levels of Evidence Working Group. The Oxford 2011 Levels of Evidence [Internet]. The Centre for Evidence-Based Medicine. 2011 [cited 7 March 2021] Available from: http://www.cebm.net/index.aspx?o=5653.

27. Guyatt GH, Oxman AD, Vist GE, Kunz R, Falck-Ytter Y, Alonso-Coello P, et al. GRADE: an emerging consensus on rating quality of evidence and strength of recommendations. BMJ. 2008;336(7650):924-6.

28. Hannon L, St. Clair T, Smith K, Fitzgerald M, Mitra B, Olaussen A, et al. Finger thoracostomy in patients with chest trauma performed by paramedics on a helicopter emergency medical service. Emerg Med Australas. 2020;32(4):650-6. https://doi.org/10.1111/1742-6723.13549.

29. Quinn N, Palmer CS, Bernard S, Noonan M, Teague W. Thoracostomy in children with severe trauma: an overview of the paediatric experience in Victoria, Australia. Emerg Med Australas. 2019;32(1):117-26. https://doi. org/10.1111/1742-6723.13392.

30. Aylwin CJ, Brohi K, Davies GD, Walsh MS. Pre-hospital and in-hospital thoracostomy: indications and complications. Ann R Coll Surg Eng. 2008;1(90):54-7. https://doi.org/10.1308/003588408X242286.

31. Roberts DJ, Leigh-Smith S, Faris PD, Blackmore C, Ball CG, Robertson HL, et al. Clinical presentation of patients with tension pneumothorax: a systematic review. Ann Surg. 2015;261(6):1068-78. https://doi.org/10.1097/ SLA.0000000000001073.

32. Richter T, Ragaller M. Ventilation in chest trauma. J Emerg Trauma Shock. 2011;4(2):251-250. https://doi.org/10.4103/0974-2700.82215.

33. Dickson RL, Gleisberg G, Aiken M, Crocker K, Patrick C, Nichols T, et al. Emergency medical services simple thoracostomy for traumatic cardiac arrest: postimplementation experience in a ground-based suburban/rural emergency medical services agency. J Emer Med. 2018;55(3):66-371. https://doi.org/10.1016/j.jemermed.2018.05.027.

34. Kesieme EB, Dongo A, Ezemba N, Irekpita E, Jebbin N, Kesieme C. Tube thoracostomy: complications and its management. Pulm Med. 2011;16:2012. https://doi.org/10.1155/2012/256878.

35. Gawande A. The checklist manifesto. London: Profile Books Ltd; 2011.

36. Amaral CB, Ralston DC, Becker TK. Prehospital point-of-care ultrasound: a transformative technology. SAGE Open. 2020:8:1-6. https://doi.org/10. 1177/2050312120932706.

37. Bøtker MT, Jacobsen L, Rudolph SS, Knudsen L. The role of point of care ultrasound in prehospital critical care: a systematic review. Scand J Trauma Resusc Emerg Med. 2018. https://doi.org/10.1186/ s13049-018-0518-x.

38. Press GM, Miller SK, Hassan IA, Alade KH, Camp E, Del Junco D, et al. Prospective evaluation of prehospital trauma ultrasound during aeromedical transport. J Emer Med. 2014;47(6):638-45. https://doi.org/10.1016/j.jemer med.2014.07.056.

\section{Publisher's Note}

Springer Nature remains neutral with regard to jurisdictional claims in published maps and institutional affiliations.
Ready to submit your research? Choose BMC and benefit from:

- fast, convenient online submission

- thorough peer review by experienced researchers in your field

- rapid publication on acceptance

- support for research data, including large and complex data types

- gold Open Access which fosters wider collaboration and increased citations

- maximum visibility for your research: over $100 \mathrm{M}$ website views per year

At BMC, research is always in progress.

Learn more biomedcentral.com/submissions 